\title{
MODERATION EFFECT OF SOFTWARE ENGINEERS' EMOTIONAL INTELLIGENCE (EQ) BETWEEN THEIR WORK ETHICS AND THEIR WORK PERFORMANCE
}

\author{
Shafia Khatun and Norsaremah Salleh \\ Department of Computer Science, Kulliyah of Information and \\ Communication Technology (KICT), International Islamic \\ University Malaysia (IIUM), Kuala Lumpur, Malaysia
}

\begin{abstract}
In today's world, software is being used in every sector, be it education, healthcare, security, transportation, finance and so on. As software engineers are affecting society greatly, if they do not behave ethically, it could cause widespread damage, such as the Facebook-Cambridge Analytica scandal in 2018. Therefore, investigating the ethics of software engineers and the relationships it has with other interpersonal variables such as work performance is important for understanding what could be done to improve the situation. Software engineers work in rapidly-changing business environments which lead to a lot of stress. Their emotions are important for dealing with this, and can impact their ethical decision-making. In this quantitative study, the researcher aims to investigate whether Emotional Intelligence (EQ) moderates the relationship between work ethics of software engineers and their work performance using hierarchical multiple regression analysis in SPSS. The findings have found that EQ does significantly moderate the relationship between work ethics and work performance. These findings provide valuable information for improving the ethical behaviour of software engineers.
\end{abstract}

\section{KEYWORDS}

Software engineers, emotional intelligence, work ethics, work performance, quantitative study

\section{INTRODUCTION}

\subsection{Ethics in Information and Communication Technology (ICT)}

Development of software has become a core element in today's Information and Communication Technology (ICT) based society [1] [2]. Governments, educational institutions, healthcare organizations, national security, transportation, and many other sectors are using systems that involve software. Without the software, these systems would not function. These systems are benefiting society greatly, and in the current global COVID-19 pandemic, their benefits can be felt even more. Many of the services these systems provide can be accessed online from a distance which is crucial during the current pandemic [3]. Therefore, it can be said that the software engineers behind the development of these software are impacting society greatly [1] [2] [4]. As they have the power to affect society, they also have a duty to exercise that power responsibly and ethically or it could cause widespread damage. There are many instances in the past where this has happened.

David C. Wyld et al. (Eds): NLP, JSE, MLTEC, DMS, NeTIOT, ITCS, SIP, CST, ARIA - 2020

pp. 153-168, 2020. CS \& IT - CSCP 2020

DOI: $10.5121 /$ csit.2020.101412 
In March 2018, news all over the world exploded with the Facebook-Cambridge Analytica scandal. Cambridge Analytica, a data analytics (involving software), political, advertising and consulting company based in the UK, was found to have harvested the personal data of millions of people's Facebook profiles without their consent and used it to influence a variety of political campaigns. It resulted in a huge public outcry, a massive fall in Facebook's stock price, Mark Zuckerberg (the founder of Facebook) had to testify in front of the United States' congress, and there were calls for tighter regulation on software companies' use of data [5].

The year before, in 2017, the Volkswagen emissions scandal occurred. Volkswagen was found to have used a defeat device to cheat on emissions tests mandated by the Environmental Protection Agency (EPA) and the California Air Resources Board (CARB) to sell approximately 590,000 diesel vehicles in the US. Misinformation was purposely being generated by software that was developed and implemented by professionals who were knowingly part of this unethical and illegal act [4].

Another example of software misuse is ransomware. According to Lord [6], more than 7,600 ransomware attacks were reported to the Internet Crime Complaint Centre (IC3) between 2005 and March of 2017. In 2015 alone, the IC3 received 2,453 ransomware complaints that cost victims over \$1.6 million. According to Lord [6], these figures only represent the attacks reported to the IC3; the actual number of ransomware attacks and costs is much higher. Also, during the current pandemic, countries across the globe have reported an increase in ransomware attacks [3]. Ransomware is a form of malicious software from cryptovirology that threatens to publish the victim's data or perpetually block access to it unless a ransom is paid [7]. This means that people who are able to develop software are intentionally using their skills for unethical purposes. This illegal extortion of money is already a great crime. But when it puts people's lives at risk, the crime becomes even worse. In 2017, in May, a ransomware attack in the UK caused the closure of many of the emergency units in hospitals in the UK, endangering patients [4].

These examples are only a few of the many incidences where software is developed and used for illegal or unethical reasons. Ethics can be simply defined as "a system of moral principles" [8, p. 1]. They influence "how people lead their lives, for life is an unbroken stream of decision-making and ethics are concerned with what is the right moral choice, for individuals and for society" [8, p. 1]. Within an organization, staff behaving ethically would mean that they complete their work responsibly with integrity and honesty, that there work is beneficial and not harmful, and "adhere to policies and rules while working to meet the aims" of the organization $[8, \mathrm{p} .1]$.

Rogerson et al. [4] said that the consideration of ethics in the Information Technology (IT) industry is often neglected until events like those described earlier occur. In the aftermath of these incidences, members of the public reignite the discussion on the ethical standards of IT companies. They call for tighter regulations on them. However, even with them voicing these demands time and time again, not enough is being done. In a keynote speech at ICSE 2015, Grady Booch put forward the notion that "every line of code has a moral and ethical implication." Ferrario et al. [9] said that "anything digital is inevitably affected by values: the organizational values of the project sponsor, the values of the research partners, and the values of each developer and designer" [p. 1]. Thomson and Schmoldt [10] mentioned that, from an ethical perspective, technology improvement should protect human values while improving computer software. However, as said before, the presence of human values in software engineering (SE) is usually neglected or invisible until the widespread consequences of breaching them are felt [4] [9]. In education and research as well, ethics are not given enough emphasis [11]. Logan and Clarkson [12], in 2005, did a review of programs offered by universities in information security and found that there was a pattern of "strong technical content and the absence of an ethics and computer law course" [pp. 157-161]. In 2017, Rogerson et al. [4] said that in reviewing topics 
covered by several international and national information systems conferences and textbooks, the topic of ethics is totally missing or minimally represented. This is very surprising as, in the IT world, ethics is a very crucial issue. It can be observed that not much has improved between 2005 and 2017. These findings show that there is a dire need to increase awareness, interest and action on the ethical dimension of ICT in education, in industries, and in research.

One way of taking action in research is to investigate the relationship between the ethics of software engineers and other variables, especially interpersonal variables of software engineers. Günsel and Açikgöz [13] said that in the context of organizational behavior (OB), "software development remains a poorly understood process" [p. 14]. Based on what previous studies have mentioned and what the researchers have reviewed in past literature, research on the interpersonal characteristics and competencies of software engineers are scant [14] [15], especially in relation to their ethics. With the recurring incidents of unethical behaviour in the IT/SE industry, educators, practitioners and researchers are becoming more aware that more effort and attention should be given to understanding the software engineers developing the software [14]. If the relationships between the ethics of software engineers and their interpersonal characteristics are investigated, this will help in understanding the dynamics surrounding the ethics of software engineers and what can be done to improve the situation.

Therefore, in this study, the researchers aim to investigate the ethics of software engineers and how it is related with other interpersonal variables as this may give valuable information on what can be done to improve the situation. Two such variables are the emotional intelligence (EQ) of software engineers and their work performance. The rationale for choosing these variables is explained in the next section.

\subsection{Emotional Intelligence (EQ) and Work Performance}

There is an evident relationship between an employee's individual characteristics, such as his/her ethical beliefs, and unethical behaviour at the workplace [16]. Additionally, there may also be situational characteristics that can cause an employee to behave unethically. Affective Events Theory (AET) which was developed by organizational psychologists, Weiss and Cropanzano [17], explains that emotions experienced by workers at the workplace have an influence on handling workplace situations which can be positive or negative. Software engineers work in rapidly-changing business environments [18] that are demanding and competitive [13] which results in them facing a lot of pressure which leads to stress [15]. Rezvani and Khosravi [15] say that increasing levels of stress affects a software engineer's "ability to self-regulate their feelings and understanding" [p. 139]. As humans, software engineers not only bring their personalities, ethical beliefs, knowledge and skills to their work, they also bring their emotions [19]. Emotional intelligence (EQ) was first described formally by Salovey and Mayer [20]. They defined it as "the ability to monitor one's own and others' feelings and emotions, to discriminate among them and to use this information to guide one's thinking and actions" [p. 189]. Later on, researchers came up with more detailed definitions such as "the set of abilities that enable a person to generate, recognize, express, understand, and evaluate their own, and others' emotions in order to guide thinking and action that successfully cope with emotional demands and pressures" [21, p. 72]. The complex nature of a software engineer's job calls for intense social interactions, and such interactions produce many emotions [22]. In stressful situations, a software engineer with a higher EQ is more likely to manage their emotions better, leading to lower levels of stress [15] [23]. Previous studies have found that employees with higher EQs had positive correlations with work performance [15] [24] [25] [26] [27], team performance [13] [28] [29], job satisfaction [30], and successful software projects [13] [31] [32]. In fact, studies have shown that skills associated with EQ are twice as important for career success as intelligence (IQ) or technical skills [33] [34]. Holt and Jones [35] highlighted the economic value of EQ: "In the age of information and highly 
specialized work teams, emotional intelligence is becoming a vital skill as people must accomplish their work by collaborating with each other, and their ability to communicate effectively becomes as critical, if not more critical, as technical skills and capabilities" [p. 15].

Furthermore, Conservation of Resources (COR) theory [36], as explained by Rezvani and Khosravi [15], describes that "people aim to keep, safeguard, and construct resources. Resources are defined as objects, conditions, personal abilities, and attributes or energies in which the individual places value [36]. These can either be valued in themselves or facilitate the achievement of specified objectives [36]. A setting that drives an individual to anticipate a possible or actual loss of resources, or the application of resources without the potential to acquire further resources, can therefore generate stress [36] [37]" (p. 140). Adding to what was described earlier, software engineers experience many difficulties in their efforts to successfully complete their projects, especially in complex and broad projects [38], and this increases levels of stress. However, the development of personal competencies such as EQ can serve as a buffer to any loss of resources in such situations [39] [40]. EQ can be an "interpersonal support resource" $[15$, p. 140] that can be used to reduce the negative influence of stress on software engineers, especially on their ethical decision-making. Self-report EQ measures that are based on Salovey and Mayer's [20] definition of EQ, such as Schutte et al. [41] and Wong and Law [42], assert that "emotional capabilities are acquired skills that can be nurtured and enhanced" [15, p. 140]. Researchers have found that EQ is a skill that can be trained and have conducted studies where they trained students and professionals alike and found the results to be positive; their EQ did increase [43] [44]. Therefore, as EQ is a skill that can be nurtured and enhanced, and according to COR theory, EQ may be an important resource for software engineers to acquire that can assist them in dealing with the various positive and negative situations that occur in their work, especially with regards to ethical decision-making.

Additionally, in relation to ethics, researchers have pointed out that just having a high EQ is not sufficient for employees. Gibbs et al. [45] said that "without a moral compass to guide people in how to employ their gifts, emotional intelligence can be used for good or evil" [p. 67]. Also, Maak and Pless [46] argued that "responsible leaders need both emotional and ethical qualities to guide their action and behaviour in interaction" [p. 105]. Segon and Booth [47] reviewed several emotional competency inventory frameworks and found that, in terms of their definitional constructs, it is possible for an employee to display high EQ but still be an unethical individual; they demonstrated this through analyzing several high-profile cases of business leaders who were praised by the public but were later found to have behaved unethically. They said that the frameworks did not include an ethical dimension in them. They concluded that ethics competencies must be included in the frameworks to guide EQ. And although studies exploring the relationships between ethics and EQ are scant, the few that are available have shown that the ethics of an employee were most effective when the employee had high EQ and vice versa [48] [49] [50] [51] [52].

Therefore, repeating what was said earlier, many unethical incidents have occurred in the IT industry and keep occurring. These have caused widespread damage and have led to weakening the public's confidence and reducing stakeholders' trust in the integrity of IT companies and their employees. As a result, several calls for reform and closer scrutiny of the ethics of IT companies and their employees are being made by many, including business practitioners and researchers [49]. So, more than ever, investigating the ethics of software engineers, who are key players of the IT industry, and the relationships it has with other variables are of significant importance in understanding what could be done to improve the situation. As discussed earlier, software engineers experience a lot of pressure in their jobs which can lead to high levels of stress. Based on AET [17] and COR theory [36], their emotions are important in dealing with this, and can impact their ethical decision-making [24] [48] [49] [50] [53]. Therefore, EQ is one of the 
variables that will be investigated in relation to the ethics of software engineers. Studies investigating this relationship among software engineers are scant. And previous researchers of other areas have also recommended this investigation. Holian [54] recommended that future research investigate whether ethical decisions are affected by skills associated with EQ. Also, Mulki et al. [55] proposed that future research address the impact of EQ on an individual's ethical judgment. Bay and McKeage [56] said that "it may eventually be shown that emotional intelligence is one of the variables that may explain the current gap between ethical understanding and ethical behaviour' '[p. 441].

Therefore, in this study, the researchers will investigate whether EQ moderates the relationship between the work ethics of software engineers and their work performance. The performance of employees is crucial to the overall success of a company [57], and unethical behavior of employees would definitely negatively impact this [4]. The findings of this study are expected to give empirical evidence and valuable information on the need of both work ethics and EQ in software engineers for improving their ethical behaviour in their work.

\section{RELATED WORK}

\subsection{Ethics in ICT}

This subsection reviews studies conducted by other researchers that are related to ethics in ICT or SE.

Lurie and Mark [58] did a study in which they proposed "an ethical framework for software engineers that connects software developers' ethical responsibilities directly to their professional standards" [p. 1]. They said that the application of this ethical framework can override the traditional contrast between professional skills and ethical skills which is present in engineering professions. They say that this will improve the engineer's professionalism and ethics. They called it Ethical-Driven Software Development (EDSD). They said that this approach will be more effective than the usual approach in professional ethics that "advocates stand-alone codes of ethics" [p. 1].

Barn [59], proposed that, in light of recent scandals like the Volkswagen-emissions scandal, values should be included in software development as a non-functional requirement. They suggested that "values accompanied by an appropriate framework derived from non-functional requirements" [p. 1] can be used by software engineers as a means for discussion of ethical issues of the design of software. They did a case study on Volkswagen and a qualitative analysis of the views of software engineers from Reddit discussion forums and found that the Volkswagen case study really demonstrated the need of ethics in SE practice, while developers on Reddit were "relatively subdued" [p. 10] in their discussions of ethical issues; they did not give ethics the attention it should be given.

Wilk [60] conducted a study in which they proposed a course for undergraduates, Law for Computer Professionals. They said that it is crucial for students to have a good understanding of "ethics, law, policy, regulation, and responsible software development" [p. 94]. They described the curriculum of the course which consists of "legal aspects, ethical aspects, and professional responsibility" [p. 94]. They also discussed curricular guidelines by the ACM and IEEE. Several related issues and challenges that computer practitioners should address are also mentioned.

A study done by Aydemir and Dalpiaz [1] presented ethics-aware SE in which the expected "ethical values of stakeholders are captured, analysed and reflected in software specifications and 
in the SE processes" [p. 1]. They argued that SE is a field that has humans at its centre; software is produced by humans for humans. They further stated that other fields that are to do with nonsoftware goods are taking ethical concerns very seriously, like, with regards to how products are produced, "Do subcontractors use child labour? Is fair payment guaranteed?" [p. 1], also, in the field of environment and food, "What is the carbon footprint?... Are there any ingredients that could lead to addiction?" [p. 1]. So, they want similar questions to be asked for software products. They are saying that ethics need to be considered in the decision-making process of every phase of SE. They proposed a framework that can help stakeholders in analysing ethical concerns "in terms of subject (software artefact or SE process), relevant value (diversity, privacy, autonomy etc.), and threatened object (user, developer etc.)" [p. 1]. They also introduce a roadmap that describes the required steps through which SE researchers and practitioners can fully implement ethics-aware SE.

Another study by Karim, Al Ammar and Aziz [61] did a review of work already done in SE related to practicing a code of ethics. They wanted to fill the gap in research in this area regarding the actual use of Software Engineering Code of Ethics (SWECOE) in the practice of SE. Also, they developed a framework as a means for future research and for practicing ethics in the actual phases of SE through the Software Development Life Cycle (SDLC). Their findings show that, although there are quite a lot of research on SWECOE, the reality is that, practically, a code of ethics is "difficult and complicated to implement in the actual work environment" [p. 290]. With their developed framework, they aim to make it easier for software engineers to implement ethics in their work.

Melo and Sousa [62] presented a paper that aimed to examine SE programs. They said that "millennial software engineers must be prepared to make ethical decisions, think critically, and act systematically" [p. 40] in order to produce the best software. They said that this present situation requires constant changes in education and curricula, as wrong decisions in software engineers can lead to major social impacts. So, after examining current SE programs, they proposed a conceptual framework for examining cyberethics education and a number of suggestions on how to incorporate it into SE curricula.

Kumar and Kremer-Herman [11] wrote a paper in which they presented their experiences of incorporating ethics and societal impact in computing through implementing three different courses. They said that, as there is a rising need for there to be more awareness of ethics in the development of ICTs, changes need to occur at the education level for more effective consciousness of ethics in ICT. In the three courses that they implemented, they applied innovative practices such as role playing, case studies, ethical frameworks, ethics scenario development, service learning and so on. In their results, they found that it was not hard to include ethics and societal impact in the three courses. They found that it helped students to consider how their technology would affect society, and felt more ownership of their ethical responsibility. They conclude that their approaches in these three courses are feasible and help in improving ethical awareness among students.

Wood [74] conducted a study in which they explored the relationships between ethics training and decision-making/moral reasoning of IT specialists. They said that following ethical standards is really important when using information systems to prevent negative impacts. So, they wanted to study whether ethics training can improve the ethics of IT specialists. They used two surveys to collect data from a group of IT specialists from different occupations. In their results, among other findings, they found that "there is a positive significant relationship between ethics training and ethical decision making and moral reasoning" [p. 55] and that "there is a significant positive relationship between frequency of training and ethical decision making and moral reasoning" [p. 55]. They concluded that their findings show that ethics training can improve ethical decision- 
making and moral reasoning of IT specialists. Therefore, ethics training should be implemented in IT/SE industries. This will help in reducing the occurrence of unethical incidents.

Xenos and Velli [63] wrote a paper in which they presented the Ethics Game, a storytelling game in which the players encounter ethical issues that are to do with software engineering. What the players choose will affect how the story will continue. They used this Ethics Game as a tool to mediate learning activity in 144 students in a software engineering course. The findings of their study show that students displayed improvement in their knowledge of software engineering ethics through playing the game. The students found the game to be "a useful educational tool and of high usability" [p. 579]. The researchers conclude that they will improve the game to include other issues of software engineering so that it can become a comprehensive and usable tool through which students can enhance their practical knowledge on ethics in software engineering.

Based on the related work reviewed above, it can be observed that there has been an increase in the amount of research done in the area of ethics in ICT or SE. Many of the studies focused on discussing ethical issues or dilemmas in ICT or SE and have proposed possible solutions. Other studies focused on introducing new ethics courses for universities, introducing new frameworks or codes of ethics, revising existing codes of ethics and so on. However, there is a necessity to investigate the ethics of software engineers themselves and the relationships it has with other interpersonal variables. This is very important for understanding the dynamics that surround the ethics of software engineers and what could be done to minimize the occurrence of unethical incidents in the IT/SE industry.

\subsection{Emotional Intelligence (EQ)}

This subsection reviews previous studies related to EQ that are relevant to the area of this research.

Chowdhury [51] wrote an article studying the relationships between emotional intelligence (EQ) and consumer ethics. They investigated the effects of different aspects of EQ on consumers' ethical beliefs. 500 Australian consumers completed an online questionnaire that measured EQ, consumers' ethical beliefs and personal moral philosophies. Their results showed that the "ability to appraise and express emotions in oneself is directly negatively related" to unethical consumer beliefs, and the "ability to appraise and express emotions in oneself is directly positively related" to ethical/doing-good beliefs, and the "ability to appraise and recognise emotions in others" is also directly positively related to ethical/doing-good beliefs. It can be observed that emotions have a significant effect on consumers' ethical decision-making. They suggested that public policies be made that allows the EQ of consumers to be developed such as creating social and emotional learning (SEL) programmes in educational institutions as well as EQ training at the workplace.

Yadav, Dubey, and Ali [64] wrote a paper in which they investigated the role EQ and occupational stress play in moral decision-making. They said that previous research has found that stress can affect the quality of decision-making and increase unethical behavior. So, in this study they aim to explore whether EQ can reduce stress and improve ethical behavior. They collected data from 177 marketing executives using questionnaires. In their results, they found that EQ is positively related with moral decision-making, and occupational stress is inversely related to EQ and moral decision-making. They also found that occupational stress mediates the relationship between EQ and moral decision-making. They concluded that, as good EQ significantly affects moral decision-making, organizations in different sectors should administer EQ training to their employees. 
Lee, Chan and Lee [65] conducted research in which they investigated the relationship between EQ and job satisfaction among IT professionals. They say that EQ has been studied extensively among other professions such as nurses, teachers, medical professionals and so on, but there are few studies on IT professionals. They further explain that it may seem that EQ is not important to IT professionals as their jobs are technical but on further inspection, it can be observed that the work they do requires a lot of social interaction such as interacting with colleagues, stakeholders, and customers. In order to communicate and complete all of their tasks, their soft skills are important. They said that, "A high level of EQ helps IT professionals to be adept in understanding their job requirements and enables them to work more effectively with people to achieve their work objectives" [p. 140]. Their main motivation of this study is to understand better the turnover of IT professionals. They said that "Turnover is endemic and problematic in the IT industry. It disrupts operations and organizations incur high costs in recruiting and training new employees" [p. 140]. They say that previous research has found that job satisfaction contributes largely to turnover. So, they intend to investigate whether EQ affects job satisfaction. In their results, they found that personal accomplishment mediates the relationship between EQ and job satisfaction. EQ is related to job satisfaction through its indirect relationship with personal accomplishment. With these findings, they suggest that measures of EQ should be used during the staff recruitment process to see who are more likely to experience personal accomplishment. This will then lead to increasing job satisfaction and reducing turnover in IT professionals. They also suggest that EQ training be given in education and in industries.

Rezvani and Khosravi [15] conducted a study in which they investigated the impact of software engineers' EQ on their stress, trust, and performance. They explained that as software engineers work in demanding environments and face numerous difficulties in completing their projects, this increases levels of stress among them which affects "their ability to self-regulate their feelings and understanding" [p. 139] which then affects their effectiveness. So, they aim to explore whether EQ can reduce stress and instead increase trust among software engineers, which can improve their performance. In their review of the literature, they found that the number of studies focusing on software engineers' personal skills and competencies were scant. With their study, they aim to improve this lack. In their results, they found that emotionally intelligent software engineers are "more likely to manage the negative influence of stress and are more likely to trust in other team members which result in increased performance" [p. 148]. They suggest that IT/SE organizations should provide training programs that will increase the EQ skills of software engineers. They found in their research that a pre-emptive approach to reducing stress and increasing trust among employees leads to revenue growth and productivity.

From the above studies reviewed, it can be observed that EQ has a significant positive effect on work performance, job satisfaction, and ethical behaviour of people and employees of different fields. Based on the researchers' review of past studies, EQ of software engineers has not been investigated before in relation to their ethics, and work performance. This research intends to investigate these relationships. It is expected that the findings will give valuable information on the importance and need of EQ and ethics in software engineers for reducing unethical behaviour, and improving work performance, which are important for the success and progress of IT/SE organizations, and their positive contributions to society and the economy. 


\section{RESEARCH METHODOLOGY}

\subsection{Research Objective and Research Question}

The main objective of this study is to empirically investigate how emotional intelligence (EQ) moderates the relationship between work ethics of software engineers and their work performance.

Figure 1 below models this research objective. Work Ethics is the independent variable (IV), while Work Performance is the dependent variable (DV), and Emotional Intelligence (EQ) is the moderating variable (MV).

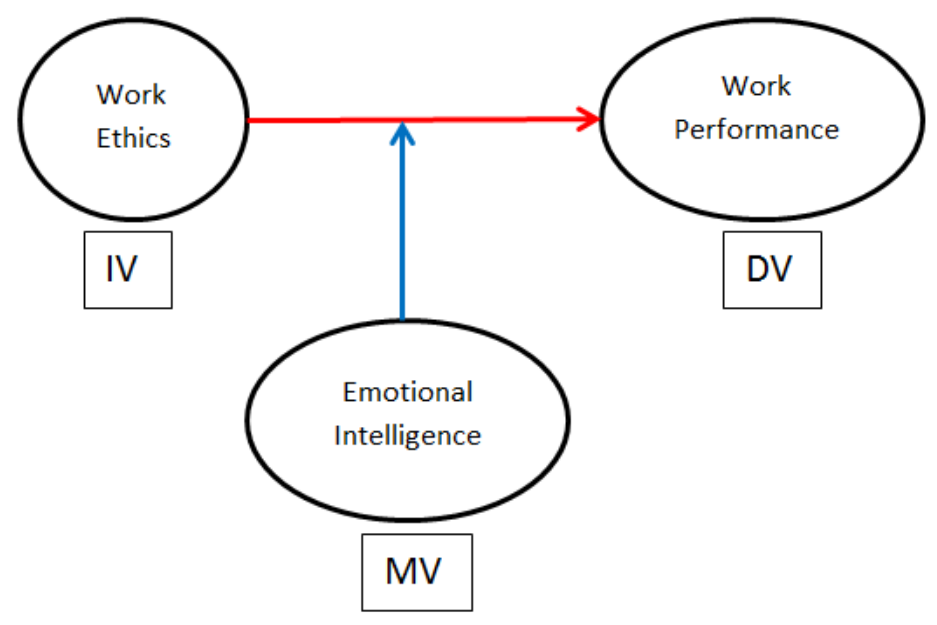

Figure 1. The research model

To address this research objective, our research question is: "How does EQ moderate the relationship between the work ethics of software engineers and their work performance?" To answer this research question and fulfill the research objective, hierarchical multiple regression analysis will be used [66]. According to [66], hierarchical multiple regression analysis is frequently used for moderation analysis for these types of research that involve interpersonal or psychological variables.

\subsection{Sample and Data Collection}

The population of this research is software engineers working in IT/SE companies. The sample was randomly taken from software engineers working in IT/SE companies via LinkedIn. The random sampling method was used in this research. More than 500 software engineers on LinkedIn were selected at random. Each of them was sent a questionnaire containing three instruments to measure three variables: Emotional Intelligence (EQ), Work Ethics, and Work Performance. A total of 170 software engineers responded and completed the questionnaire. The sample size is, therefore, $n=170$. For the random sampling technique, most statisticians agree that the minimum sample size required in order to get a meaningful result is 100 [67]. Therefore, a sample size of $n=170$ can be deemed sufficient for this study. The questionnaire was created using Google Forms. The data was collected over a period of 4 months. 


\subsection{Instruments}

The questionnaire sent to each participant contained three instruments to measure the three variables: EQ was measured using the Wong and Law Emotional Intelligence Scale (WLEIS) [68]. It has 16 questions that measure four dimensions: Self-emotions Appraisal, Regulation of Emotions, Use of Emotion, Others-emotion Appraisal; Work Ethics of software engineers will be measured using the Islamic Work Ethics (IWE) [69] instrument. It has 23 questions that measure four dimensions: Effort, Honesty, Teamwork and Accountability (the researchers would like to highlight that these four dimensions are universal work ethics); Work Performance will be measured using the Individual Work Performance [70] instrument. This questionnaire contains 18 questions that measure three dimensions: Task Performance, Contextual Performance and Counterproductive Work Behavior. Each instrument used Likert-scale items: EQ used a 7-point Likert-scale; Work Ethics used a 10-point Likert-scale; and Work Performance used a 5-point Likert-scale.

\subsection{Data Analysis}

As all three variables in this research use Likert-scale items, they are considered to be ordinal variables. However, as each of the three variables in this research was calculated by summing the score of each question in the instrument together (the level of agreement chosen on the Likert scale for each question; for example: 1=Strongly Disagree, $2=$ Disagree and so on) to get the total score, the variables can now be treated as interval/continuous variables (as the meaning of addition relies on this property). Researchers have found that ordinal variables with five or more categories can often be used as interval/continuous variables without any harm to the analysis [71] [72] [73] [74]. As all three variables have five or more Likert-scale categories, they will therefore be treated as interval/continuous variables to conduct the data analysis of this research.

After collection of data, data analysis was conducted using IBM SPSS Statistics version 22. In order to investigate how EQ moderates the relationship between Work Ethics and Work Performance, moderation analysis was conducted using hierarchical multiple regression [75]. All the assumptions necessary for conducting hierarchical multiple regression on the data of this research were met [75]. Laerd Statistics [75] was referred to for the analysis.

\section{Results}

In this section, the results of this study are presented. A total of 170 software engineers responded to the questionnaire. Therefore the sample size is $n=170$. The demographics of the sample are as follows: gender: $110(64.7 \%)$ of them were male, $60(35.3 \%)$ of them were female; age: 135 $(79.4 \%)$ of them are below 30, $29(17.1 \%)$ of them are between $30-35,3(1.8 \%)$ of them are between $36-40,2(1.2 \%)$ of them are between $41-45$, and $1(0.6 \%)$ of them is above 45 ; education: $11(6.5 \%)$ had a diploma, $2(1.2 \%)$ had an associate degree, $132(77.6 \%)$ had a bachelor's/undergraduate degree, $23(13.5 \%)$ had a master's degree, $1(0.6 \%)$ had a doctorate degree/ $\mathrm{PhD}$, and $1(0.6 \%)$ did not go to college; years of experience working in software engineering projects: $66(38.8 \%)$ had less than 2 years, $57(33.5 \%)$ had between $2-4$ years, 28 $(16.5 \%)$ had 5-8 years, $19(11.2 \%)$ had more than 9 years. 'Years of experience working in software engineering projects' is shown below in Figure 2. 

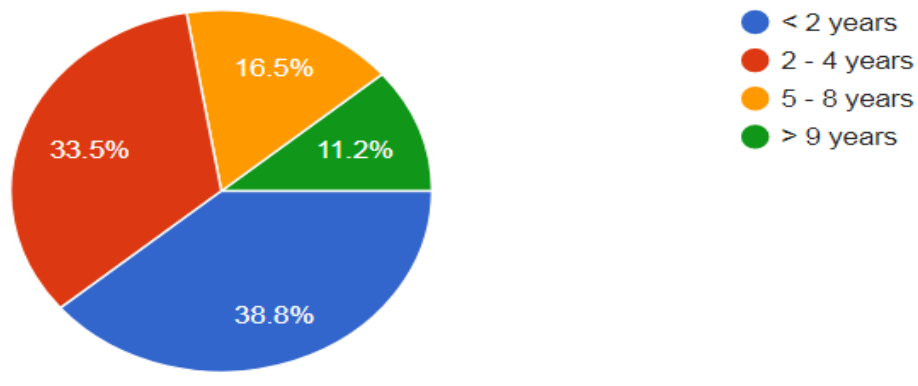

Figure 2. Percentages of years of experience working in software engineering projects of the sample under study

In this study, EQ is the moderating variable (MV), and it is also an independent variable (IV) along with Work Ethics, whereas Work Performance is the dependent variable (DV). In order to avoid multicollinearity problems (i.e. high degree of correlation between the independent variables), the IVs were mean-centred first [75]. Then the centred interaction term, EQ multiplied with Work Ethics (c_tworkethicsXeq), was calculated. And finally, the analysis was run.

There are two models in the analysis. The first model contains the IVs, c_totalworkethics (this is the mean-centred total-work-ethics) and c_totaleq (this is the mean-centred total-EQ), on their own separately. In the second model, the interaction of the IV's is added, c_tworkethicsXeq (total-work-ethics multiplied with total-EQ). Comparing the results of the first model with the results of the second model will reveal whether EQ moderates the relationship between work ethics and work performance or not. Table 1 below shows the two models. And Table 2 below shows the results:

Table 1. Variables included in Model 1 and Model 2

\begin{tabular}{|c|c|c|c|}
\hline Model & $\begin{array}{c}\text { Variables } \\
\text { Entered }\end{array}$ & $\begin{array}{l}\text { Variables } \\
\text { Removed }\end{array}$ & Method \\
\hline 1 & $\begin{array}{l}\text { c_totaleq, } \\
\text { c_totalworket } \\
\text { hics }^{\text {b }}\end{array}$ & & Enter \\
\hline 2 & $\begin{array}{l}\text { C_tworkethics } \\
\text { Xteq }^{\text {b }}\end{array}$ & . & Enter \\
\hline
\end{tabular}

a. Dependent Variable: total_workperformance

b. All requested variables entered.

Table 2. Model Summary for EQ (MV) between Work Ethics (IV) and Work Performance (DV)

\begin{tabular}{|c|c|c|c|c|c|c|c|c|c|c|}
\hline \multirow[b]{3}{*}{ Model } & \multicolumn{9}{|c|}{ Model Summary ${ }^{\circ}$} & \multirow[b]{3}{*}{$\begin{array}{l}\text { Durbin- } \\
\text { Watson }\end{array}$} \\
\hline & \multirow[b]{2}{*}{$\mathrm{R}$} & \multirow[b]{2}{*}{ R Square } & \multirow[b]{2}{*}{$\begin{array}{l}\text { Adjusted R } \\
\text { Square }\end{array}$} & \multirow[b]{2}{*}{$\begin{array}{l}\text { Std. Error of } \\
\text { the Estimate }\end{array}$} & \multicolumn{5}{|c|}{ Change Statistics } & \\
\hline & & & & & $\begin{array}{c}\text { R Square } \\
\text { Change }\end{array}$ & F Change & df1 & $d f 2$ & $\begin{array}{l}\text { Sig. F } \\
\text { Change }\end{array}$ & \\
\hline 1 & $.580^{\mathrm{a}}$ & .336 & .329 & 8.36958 & .336 & 42.341 & 2 & 167 & .000 & \multirow[b]{2}{*}{1.689} \\
\hline 2 & $.595^{\mathrm{b}}$ & .354 & .343 & 8.28100 & .018 & 4.592 & 1 & 166 & .034 & \\
\hline
\end{tabular}


A hierarchical multiple regression was run to determine if the addition of the interaction term obtained from a submaximal test improved the prediction of work performance over and above EQ and Work Ethics alone.

\section{Model Fit:}

From Table 2 above, it can be observed that Model 2 with the interaction term accounted for significantly more variance in the dependent variable, Work Performance, than just EQ and Work Ethics by themselves. $\mathrm{R}^{2}$ changed from 0.336 to $0.354, \mathrm{R}^{2}$ change $=0.018, \mathrm{p}=0.034$ (significant at the $\mathrm{p}<0.05$ level). There is significant moderation occurring.

Therefore, the addition of the interaction term to the prediction of Work Performance (Model 2) led to a statistically significant increase in $R^{2}$ of $0.018, F(1,166)=4.592, p<0.05$. Therefore, the results show that EQ does significantly moderate/strengthen the relationship between Work Ethics and Work Performance.

\section{DisCuSSION AND CONCLUSION}

From the results explained earlier, it can be confirmed that EQ significantly strengthens the relationship between work ethics of software engineers and their work performance; for software engineers who had stronger EQs, their work ethics had a stronger positive relationship with their work performance. These findings have important implications for both the IT/SE industry as well as the education sector.

As discussed earlier in the introduction, unethical incidents keep occurring in the IT/SE industry, yet not enough is being done in the IT/SE industry, in education, and in research. This study contributes in the area of research. It has investigated how work ethics of software engineers (who are key players in the IT/SE industry) is related with other interpersonal variables to understand better what could be done to improve the situation. The findings provide empirical evidence that EQ can significantly strengthen the influence of work ethics of software engineers on their work performance. Therefore, the researchers strongly suggest that steps should be taken to incorporate EQ training into IT/SE industries as well as in educational curriculums. Previous studies have found that EQ training did indeed improve the trainees' EQ [43] [44]. At the same time, steps should be taken to teach and train ethics more actively in IT/SE industries and in education. Wood [76] has found that there is a significant positive relationship between "ethics training and, ethical decision making and moral reasoning" [p. 55] among IT specialists. Therefore, training can improve the EQ and ethics of software engineers.

If steps are taken to train EQ and ethics in the IT/SE industry as well as in education, then, based on the findings of this research, it will improve the ethical behavior of software engineers in their work and thus, reduce the occurrence of unethical incidents that cause great harm to society, and instead increase beneficial contributions to society.

\section{CONTRibution AND Future Work}

This research is expected to increase the number of studies done on the interpersonal characteristics of software engineers and the relationships it has with ethics, and urge other researchers to do further research on this important and urgent area.

The limitation of this research is that all variables were quantitatively measured using selfreported questionnaires. Therefore, there may be bias in the data collected. Future research may 
try utilizing other types of research such as qualitative studies that utilize interviews, focus groups, observation, case studies and so on as methods of data collection to gather less biased data, which may bring to light additional information on the topic of this research. Longitudinal studies may also be attempted.

The researchers also recommend that further research be done on the relationships between ethics of software engineers/IT professionals and other variables such as team climate, team flexibility and so on as this will continue to increase our understanding of this important area and thus, help in curbing the rampant unethical behavior in the IT/SE world.

\section{ACKNOWLEDGEMENTS}

This study is funded by the Ministry of Higher Education Malaysia under the FRGS research grant: FRGS/1/2018/ICT01/UIAM/02/2.

\section{REFERENCES}

[1] Aydemir, F. B., \& Dalpiaz, F. (2017). A Roadmap for Ethics-Aware Software Engineering. Conference'17, July 2017, Washington, DC, USA. ACM.

[2] Jia, J., \& Xin, J. (2018). Integration of ethics issues into software engineering management education. TURC 2018. ACM.

[3] Radoini, A. (2020, May 11). Cyber-crime during the COVID-19 Pandemic. Retrieved June 11, 2020, from UNICRI: http://www.unicri.it/news/article/covid19_cyber_crime

[4] Rogerson, S., Miller, K. W., Winter, J. S., \& Larson, D. (2017). Information systems ethics challenges and opportunities. Journal of Information, Communication and Ethics in Society.

[5] Facebook-Cambridge Analytica data scandal. (2018, September 27). Retrieved September 27, 2018, from

https://en.wikipedia.org/wiki/Facebook\%E2\%80\%93Cambridge_Analytica_data_scandal

[6] Lord, N. (2018, April 6). A History of Ransomware Attacks: The Biggest and Worst Ransomware Attacks of All Time. Retrieved September 30, 2018, from Digital Guardian: https://digitalguardian.com/blog/history-ransomware-attacks-biggest-and-worst-ransomware-attacksall-time

[7] Ransomware. (2018, September 21). Retrieved September 30, 2018, from Wikipedia: https://en.wikipedia.org/wiki/Ransomware

[8] Belyh, A. (2016, March 19). Work Ethic Definition \& Elements of a Strong Work Ethic. Retrieved June 12, 2020, from Cleverism: https://www.cleverism.com/work-ethic-definition-elements-strongwork-ethic/

[9] Ferrario, M. A., Simm, W., Whittle, J., Frauenberger, C., Fitzpatrick, G., \& Purghathofer, P. (2017, May 06-11). Values in Computing. Denver: ACM.

[10] Thomson, A. J., \& Schmoldt, D. L. (2001). Ethics in computer software design and development. Computers and Electronics in Agriculture, 30(1), 85-102.

[11] Kumar, S. \& Kremer-Herman, N. (2019). Integrating Ethics Across Computing: An Experience Report of Three Computing Courses Engaging Ethics and Societal Impact through Roleplaying, Case Studies, and Service Learning. 2019 IEEE Frontiers in Education Conference (FIE)(pp. 1-5), Covington, KY, USA, doi: 10.1109/FIE43999.2019.9028568.

[12] Logan, P. Y., \& Clarkson, A. (2005). Teaching students to hack: curriculum issues in information security. SIGCSE Bull, 37(1), 157-161.

[13] Günsel, A., \& Açikgöz, A. (2013). The Effects of Team Flexibility and Emotional Intelligence on Software Development Performance. Group Decis Negot, 359-377.

[14] Kosti, M. V, Feldt, R., Angelis, L. (2014). Personality, emotional intelligence and work preferences in software engineering: An empirical study. Information and Software Technology, 56(8), 973-990. https://doi.org/10.1016/j.infsof.2014.03.004.

[15] Rezvani, A., \& Khosravi, P. (2019). Emotional intelligence: The key to mitigating stress and fostering trust among software developers working on information system projects. International Journal of Information Management, 139-150. 
[16] Robbins, S. P., \& Judge, T. A. (2013). Organizational Behavior. Prentice Hall.

[17] Weiss, H. M., \& Cropanzano, R. (1996). Affective events theory: A theoretical discussion of the structure, causes and consequences of affective experiences at work. Research in Organizational Behavior, Volume 18, pages 1-74.

[18] Lee, G., Xia, W. (2005). The ability of information systems development project teams to respond to business and technology changes: a study of flexibility measures. Eur J Inf Syst 14(1):75-92.

[19] Kelly J. R., Barsade S. G. (2001). Mood and emotions in small groups and work teams. Organ Behav Hum Decis Process 86(1):99-130.

[20] Salovey, P., \& Mayer, J. D. (1990). Emotional intelligence. Imagination, Cognition and Personality, 9, 185-211.

[21] Van Rooy, D., \& Viswesvaran, D. (2004). Emotional intelligence (A meta-analytic investigation of predictive validity and nomological net). Journal of Vocational Behavior, 65(1), 71-95.

[22] Reus T. H., Liu Y. (2004). Rhyme and reason: emotional capability and the performance of knowledge-intensive work groups. Hum Perf 17(2):245-266.

[23] Gohm, C. (2003). Mood regulation and emotional intelligence: individual differences. Journal of Personality and Social Psychology, 84(3), 594-607.

[24] Goleman, D. (1995). Emotional intelligence: why it can matter more than IQ for character, health and lifelong achievement. New York: Bantam Books.

[25] Goleman, D., Boyatzis, R., \& Mckee, A. (2002). Primal leadership. Boston: Harvard Business School Press.

[26] Dulewicz, C., Young, M., \& Dulewicz, V. (2005). The relevance of emotional intelligence for effective leadership. Journal of General Management, 30(3), 71-86.

[27] Brackett, M. A., Rivers, S. E., \& Salovey, P. (2011). Emotional intelligence: Implications for personal, social, academic, and workplace success. Social and Personality Psychology Compass, 5(1), $88-103$.

[28] Druskat, V., \& Wolff, S. (2001). Building the emotional intelligence of groups. Harvard Busines Review, 79(3), 81-90.

[29] Jordan, P., \& Troth, A. (2004). Managing emotions during team problem solving: emotional intelligence and conflict resolution. Human Performance, 17(2), 195-218.

[30] Sy, T., Tram, S., \& O'Hara, L. (2006). Relation of employee and manager emotional intelligence to job satisfaction and performance. Journal of Vocational Behavior, 68(3), 461-471.

[31] Nicholson B., \& Sahay S. (2004). Embedded knowledge and offshore software development. InfOrg 14(4):329-365.

[32] Hoegl M., Parboteeah K. P. (2007). Creativity-relevant skills and the task performance of innovation teams: how teamwork maters. J Eng Technol Manag 24:148-166.

[33] Law, K. S., Wong, C. S., \& Song, L. J. (2004). The construct and criterion validity of emotional intelligence and its potential utility for management studies. Journal of Applied Psychology, 89(3), 483-496.

[34] Cote, S., \& Miners, C. (2006). Emotional intelligence, cognitive intelligence, and job performance. Administrative Science Quarterly, 51(1), 1-28.

[35] Holt, S., \& Jones, S. (2005). Emotional intelligence and organizational performance: implications for performance consultants and educators. Performance Improvement, 44(10), 15-48.

[36] Hobfoll, S. E. (2001). The influence of culture, community, and the nested-self in the stress process: Advancing conservation of resources theory. Applied Psychology, 50(3), 337-421.

[37] Hobfoll, S. E. (1989). Conservation of resources: A new attempt at conceptualizing stress. The American Psychologist, 44(3), 513.

[38] Gupta, M., George, J. F., \& Xia, W. (2019). Relationships between IT department culture and agile software development practices: An empirical investigation. International Journal of Information Management, 44, 13-24.

[39] Hobfoll, S. E., \& Shirom, A. (2001). Conservation of resources theory: Applications to stress and management in the workplace. In R. T. Golembiewski (Ed.). Handbook of organization behavior (pp. 57-81). (2nd ed.). New York: Dekker.

[40] Holmgreen, L., Tirone, V., Gerhart, J., \& Hobfoll, S. E. (2017). Conservation of resources theory. The handbook of stress and health: A guide to research and practice, 443-457.

[41] Schutte, N. S., Malouff, J. M., Hall, L. E., Haggerty, D. J., Cooper, J. T., Golden, C. J., et al. (1998). Development and validation of a measure of emotional intelligence. Personality and individual differences, 25(2), 167-177. 
[42] Wong, C. S., \& Law, K. S. (2002). The effects of leader and follower emotional intelligence on performance and attitude: An exploratory study. The Leadership Quarterly, 13(3), 243-274.

[43] Grant, A. M. (2007). Enhancing coaching skills and emotional intelligence through training. INDUSTRIAL AND COMMERCIAL TRAINING, 257-266.

[44] Herrera, M. A., Salas, A. M., Sarmiento, L. C., Agüero, J. V., Cerdas, M. B., \& Jiménez, M. T. (2019). Development of Emotional Intelligence in Computing Students: The "Experiencia 360" Project. 2019 XLV Latin American Computing Conference (CLEI). IEEE.

[45] Gibbs, N., Park, A., \& Birnbaum, J. (1995). The EQ factor. Time, 146(4), 60-67.

[46] Maak, T., \& Pless, M. (2006). Responsible leadership in a stakeholder society- a relational perspective. Journal of Business Ethics, 66(1), 99-115.

[47] Segon, M., \& Booth, C. (2014). Virtue: The Missing Ethics Element in Emotional Intelligence. J Bus Ethics.

[48] Deshpande, S. P. (2009). A study of ethical decision-making by physicians and nurses in hospitals. Journal of Business Ethics, 90(3), 387-397.

[49] Angelidis, J., \& Ibrahim, N. A. (2011). The Impact of Emotional Intelligence on the Ethical Judgment of Managers. J Bus Ethics, 111-119.

[50] Fu, W. (2014). The impact of emotional intelligence, organizational commitment, and job satisfaction on ethical behaviour of Chinese employees. Journal of Business Ethics, 122(1), 137-144.

[51] Chowdhury, R. M. (2015). Emotional Intelligence and Consumer Ethics: The Mediating Role of Personal Moral Philosophies. J Bus Ethics.

[52] Ashraf, H., Hosseinnia, M., \& Domsky, J. G. (2017). EFL teachers' commitment to professional ethics and their emotional intelligence: A relationship study. Cogent Education.

[53] Haidt, J. (2003). The moral emotions. In R. J. Davidson, K. R. Scherer, \& H. H. Goldsmith (Eds.), Handbook of affective sciences (pp. 852-870). Cary, NC: Oxford University Press.

[54] Holian, R. (2006). Management decision making, ethical issues and emotional intelligence. Management Decision, 44(8), 1122-1138.

[55] Mulki, J., Jaramillo, J., \& Locker, W. (2009). Critical role of leadership on ethical climate and salesperson behaviors. Journal of Business Ethics, 86(2), 125-141.

[56] Bay, D., \& McKeage, K. (2006). Emotional intelligence in undergraduate accounting students: preliminary assessment. Accounting Education: An International Journal, 15(4), 439-454.

[57] Leonard, K. (2019, March 6). Importance of Employee Performance in Business Organizations. Retrieved June 13, 2020, from Chron: https://smallbusiness.chron.com/importance-employeeperformance-business-organizations1967.html\#: :text=One\%20of\%20the\%20most\%20important,and\%20will\%20seek\%20help\%20else where.

[58] Lurie, Y., \& Mark, S. (2015). Professional Ethics of Software Engineers: An Ethical Framework. Science and Engineering Ethics.

[59] Barn, B. S. (2016). Do You Own a Volkswagen? Values as Non-Functional Requirements. HCSE + HESSD 2016.

[60] Wilk, A. (2016). Cyber Security Education and Law. 2016 IEEE International Conference on Software Science, Technology and Engineering (pp. 94-103). IEEE.

[61] Karim, N. A., Al Ammar, F., \& Aziz, R. (2017). Ethical Software: Integrating Code of Ethics into Software Development Life Cycle. 2017 International Conference on Computer and Applications (ICCA) (pp. 290-298). IEEE.

[62] Melo, C. d., \& Sousa, T. C. (2017). Reflections on Cyberethics Education for Millennial Software Engineers. 2017 IEEE/ACM 1st International Workshop on Software Engineering Curricula for Millennials (SECM) (pp. 40-46). IEEE.

[63] Xenos M., \& Velli V. (2020). A Serious Game for Introducing Software Engineering Ethics to University Students. In: Auer M., Tsiatsos T. (eds) The Challenges of the Digital Transformation in Education. ICL 2018. Advances in Intelligent Systems and Computing, vol 916. Springer, Cham. https://doi.org/10.1007/978-3-030-11932-4_55.

[64] Yadav, S., Dubey, N., \& Ali, A. A. (2015). Emotional Intelligence and Moral Decision Making: Mediating Role of Occupational Stress. Journal of Contemporary Psychological Research, 53-59.

[65] Lee, P., Chan, B., \& Lee, J. (2017). Emotional Intelligence and Information Technology Professionals. Proceedings of the 2017 IEEE IEEM (pp. 140-144). IEEE. 
[66] Fairchild, A. J., \& McQuillin, S. D. (2010). Evaluating mediation and moderation effects in school psychology: a presentation of methods and review of current practice. Journal of school psychology, 48(1), 53-84. https://doi.org/10.1016/j.jsp.2009.09.001

[67] Bullen, P. B. (2020). How to choose a sample size (for the statistically challenged). Retrieved October 10, 2020, from tools4dev: http://www.tools4dev.org/resources/how-to-choose-a-sample-size/

[68] Wong, C. S., \& Law, K. S. (2002). The effects of leader and follower emotional intelligence on performance and attitude: An exploratory study. The Leadership Quarterly, 13(3), 243-274.

[69] Kamaluddin, Norlela, \& Ab. Manan, Siti Khadijah (2010). The conceptual framework of Islamic work ethic (IWE). Malaysian Accounting Review, 9(2): 57-70.

[70] Koopmans, L. (2014). Measuring Individual Work Performance. CPI Koninklijke Wöhrmann, Zutphen.

[71] Johnson, D.R., \& Creech, J.C. (1983). Ordinal measures in multiple indicator models: A simulation study of categorization error. American Sociological Review, 48, 398-407.

[72] Norman, G. (2010). Likert scales, levels of measurement and the "laws" of statistics. Advances in Health Sciences Education, 15(5), pp. 625-632. Retrieved from: https://link.springer.com/article/10.1007\%2Fs10459-010-9222-y\#citeas.

[73] Sullivan, G. \& Artino Jr., A. R. (2013). Analyzing and Interpreting Data From Likert-Type Scales. Journal of Graduate Medical Education. 5(4), pp. 541-542.

[74] Zumbo, B. D., \& Zimmerman, D. W. (1993). Is the selection of statistical methods governed by level of measurement? Canadian Psychology, 34, 390-400.

[75] Laerd Statistics (2015). Hierarchical multiple regression using SPSS Statistics. Statistical tutorials and software guides. Retrieved from https://statistics.laerd.com/

[76] Wood, K. L. (2019). An Exploration into the Relationships of Ethical Decision Making and Moral Reasoning Among IT Specialists with Ethics Training, Education, and Ethical Leadership. In Proceedings of the 2019 on Computers and People Research Conference (SIGMIS-CPR '19). Association for Computing Machinery, New York, NY, USA, 50-56. DOI:https://doi.org/10.1145/3322385.3322398.

\section{AUTHORS}

Shafia Khatun completed her primary and secondary education in Malaysia. She went to MAZ International School for her primary education, and International Islamic School Malaysia for her secondary education. She later attended International Islamic University Malaysia (IIUM) to complete her Bachelor's degree in Computer Science. She worked in a software company, Madcat World Sdn. Bhd., for half a year. She is currently doing her Master's degree in Computer Science at IIUM. This research paper presents part of the research conducted for her Master's degree.

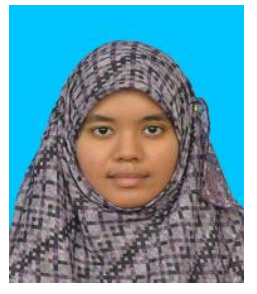

Dr. Norsaremah Salleh is an Associate Professor at the Department of Computer Science, International Islamic University Malaysia (IIUM) and the Director of Information Technology Division at IIUM. Her research interests include the areas of empirical software engineering (SE), evidence based SE, human and social aspects of $\mathrm{SE}$ and Computer Science/ SE education. She received her PhD in Computer Science from the University of Auckland, New Zealand. Contact her at norsaremah@iium.edu.my

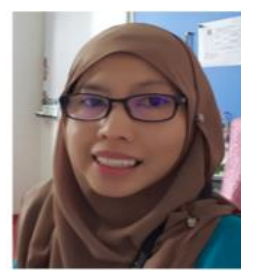

(C) 2020 By AIRCC Publishing Corporation. This article is published under the Creative Commons Attribution (CC BY) license 